\title{
The passing adventure of Anzer Thyme (Thymus praecox Opiz subsp. caucasicus (Wild. Ex Ronniger) Jalas var. caucasicus) from the Highland to the Field
}

\author{
Emine Yurteri \\ Field Crops Department, Faculty of Agriculture and Natural Sciences, \\ Recep Tayyip Erdoğan University, PO box 53300, Rize, Turkey \\ E-mail: emine.yurteri@erdogan.edu.tr \\ Fatih Seyis (Corresponding author) \\ Field Crops Department, Faculty of Agriculture and Natural Sciences, \\ Recep Tayyip Erdoğan University, PO box 53300, Rize, Turkey \\ E-mail: fatih.seyis@erdogan.edu.tr \\ Aysel Ozcan \\ Field Crops Department, Faculty of Agriculture and Natural Sciences, \\ Recep Tayyip Erdoğan University, PO box 53300, Rize, Turkey \\ E-mail: aysel.ozcan@erdogan.edu.tr
}

The research is financed by the Research Fund of the Recep Tayyip Erdoğan University

\begin{abstract}
The curative resource Anzer Thyme, an important member of the Lamiaceae family, is natural spread in the Anzer highland of Rize and is an important product with future potential for regional people and also for the world because of its active ingredients in its essential oil. Thymus praecox Opiz subsp. Caucasicus (Wild. ex Ronniger) Jalas var. caucasicus was collected from different altitudes of Anzer higland (1534m, $1750 \mathrm{~m}$ ve $2106 \mathrm{~m}$ ) and cultivated in the field. The essential oil of this material contains $39-42.12 \%$ thymol, 20.76-53.57 \% carvacrol and 11.65-31.37\% $\alpha$-terplnyl acetate. The regional people uses it in specially meat dish, it has also use as taste and aroma additives in pizzas, soups and salads. It has also use specially as stimulant of the circulatory system as infusions, as antispasmotic and diuretic.

If Thymol is used in low doses it is known as gastric, expectorant and nerve intesifier; if it is used in high doses as antiseptic and worm degrador. Its oil is highly antioxidant and is added to rapid degrading products to prevent their degradation. Besides these properties the oil of Anzer Thyme has antibacterial and antifungal properties due to carvacrol and thymol essential oil constituents. It is promising to adapt Anzer thyme to field conditions and also promising to have the possibility select variety canditates based on their essential oil components. İt is important to discover the importance of Anzer thyme regarding human health for regional people and country economy.
\end{abstract}

Keywords: China insurance industry, Foreign fund, Challenge

DOI: $10.7176 / \mathrm{JSTR} / 5-3-05$

\section{Şifa Kaynağı Anzer Kekiği (Thymus praecox Opiz subsp. caucasicus (Wild. Ex Ronniger) Jalas var. caucasicus)'nin Yayladan Tarlaya Geçiş Serüveni}

\section{Giriș}

Tıbbi ve aromatik bitkiler hastalıkların önlenmesi, iyileştirilmesi ve sağlığın sürdürülmesi için ilaç olarak geleneksel ve modern tıpta kullanılmaktadır. Aynı zamanda besin takviyeleri, bitkisel çay, baharat ve çeşni olarak beslenmede faydalanılmaktadır. Vücut bakım ürünleri parfümeri ve kozmetikte 
kullanılmasına ilaveten böcek ilaçları ve parlatıcı sanayinde değerlendirilmektedir. Bu bitkilerin bir veya birden fazla kısımlarından (kök, kök-sap, yumru, gövde veya odunsu yapı, kabuk, yaprak, çiçek, meyve, tohum ve herba) drog yaprak olarak yararlanılmaktadır. Tıbbı bitkilerin ilaç olarak tedavi amaçla kullanımı oldukça eskilere dayanmaktadır. Özellikle İbni Sina'nın 930-1037 yıllarında kaleme aldığı ElKanun Fi-t Tıbb adlı eserinde bir çok bitkinin ilaç olarak kullanılması, hangi organ ve hangi hastalıklarda tedavi edici özelliğinin olduğuna ilişkin bir çok bilgiye yer verilmiştir. Kekiğin ise eritici ve parçalayıcı özelliğinin olduğu, donmuş kanı bile parçalayabildiği, kışın içildiğinde soğuktan titremeyi önlediği, siğilleri yok ettiği, balgam söktürücü, kaburga ağrılarını dindirici, görme gücünü artırıcı, iştah açıcı, sindirim kolaylaştırıcı, kurt döktürücü ve idrar söktürücü özelliklerinden bahsedilmiştir (Kahya, 2017). Ülkemizde son yıllarda tıbbı ve aromatik bitkilere verilen devlet desteğiyle beraber üretim alanı ve üretim miktarında gözle görülür artışlar olmuştur. 2011 yılı toplam ekili alan 1.621 .387 da iken, 2015 yllında 2.130.265 da yükselmiştir. Ekili alanın artmasıyla üretim miktarında da aynı şekilde artı̧̧ söz konusu olmuştur. 2011 y1lında 405.097 ton olan üretimimiz, 2015 y1lında 513.794 ton olarak gerçekleşmiştir. Üretimimiz içinde kekik, nane ve adaçayı'nın payı ise sadece \% 19 olmuştur. Türkiye'nin ihracatında önemli olan 26 bitkinin ihracat değeri ile uçucu yağların ihracat değeri toplamı 2001 y1lında 52 milyon dolar olarak gerçekleşmiş̧en, 2012-2016 yılında 169-137 milyon dolar seviyesinde değişmiş̧ir. Tıbbi bitki ihracatı yapan 110 ülke arasında Türkiye 18. sırada yer almaktadır (Aydın vd, 2014). Türkiye, Doğu ve Güney Doğu Avrupa ülkeleri arasında ihracatta 6. sırada, ithalatta 15. sırada yer almıştır (Anonim, 2017b).

Doğu Karadeniz bölgesinde bitki tür çeşitliliği bakımından en zengin olan illerin başında Rize ili gelmektedir. Tübitak tarafindan desteklenen bir araştırmada Rize ilinde, toplam 1430 bitkisel tür çeşitliliği, bunlardan 15 adedi Türkiye florası için yeni kayıtlar olduğu, 4 bitki taksonunun ise bilim dünyası için yeni olduğu, ayrıca 110 taksonun da Türkiye için endemik olduğu saptanmıştır (Güner vd, 1987).

Lamiaceae familyasına mensup $15^{\prime}$ den fazla bitki türü Türkiye'de "kekik" olarak tanımlanmaktadır. Ancak özellikle thymol/carvacrol tipi uçucu yağ içeren türler "kekik" olarak kabul edilmektedir. Bu türler arasındaki bitkilerin büyük bir çoğunluğu Thymus cinsine aittir. Türkiye florası, içerdikleri etken madde yönünden önemli olan ve ekonomik anlamda pazar payı yüksek olan Thymus, Origanum, Satureja, ve Thymbra cinslerine ait türleri barındırmaktadır (Thymus $=58$ takson, Origanum $=33$ takson, Satureja $=15$ takson ve Thymbra $=4$ takson) (Özgüven $\&$ Tansi, 1998).

Bilindiği gibi, yetiştirme ve sslah çalışmalarında ve özellikle de ilaç ve baharat bitkilerinde kaliteli ürün ve drog eldesi amaçların başında gelmektedir. Ülkemizde özellikle tarla bitkileri alanında genetik materyalin toplanması, karakterizasyonu ve tescili ile ilgili önemli destekler sağlanmaktadır. $\mathrm{Bu}$ desteklerden dolayı tıbbi ve aromatik bitkilerin karakterizasyonu, kültürünün yapılması ve çeşit geliştirme ile ilgili çalışmalar hız kazanmıştır (Ceylan, 1995)

\section{Materyal ve Metod}

\subsection{Araştırma yerinin genel özellikleri}

Bitkisel materyallerin toplandığı Rize ili Kuzeydoğu Anadolu'da, Doğu Karadeniz kıyı şeridinin doğusunda, $40^{\circ}-22^{1}$ ve $41^{\circ}-28^{1}$ doğu meridyenleri ile $40^{\circ}-20^{1}$ ve $41^{\circ}-20^{1}$ kuzey paralelleri arasinda yer alır. Batıdan Trabzon'un Of, güneyden Erzurum'un İspir, Doğudan Artvin'in Yusufeli ve Arhavi ilçeleri ile Kuzeyden Karadeniz tarafindan çevrili olup göller hariç yüzölçümü $3922 \mathrm{~km}^{2}$ ' dir. Şekil 1 ' de bitki materyalinin toplandığı Anzer Yaylasından görüntüler gösterilmektedir.

\subsection{Bitki materyali}

Rize ilinin doğal florasında yayılış gösteren Lamiaceae familyasına mensup ekonomik değere sahip Thymus praecox Opiz subsp. caucasicus (Wild. ex Ronniger) Jalas var. caucasicus Anzer yaylasının 3 farklı yükseltisinden toplanan (TPCA1, TPCA2 ve TPCA3) ve çoğaltılan genetik materyalin (Çizelge 1) etken maddeleri araştırılmıştır. 

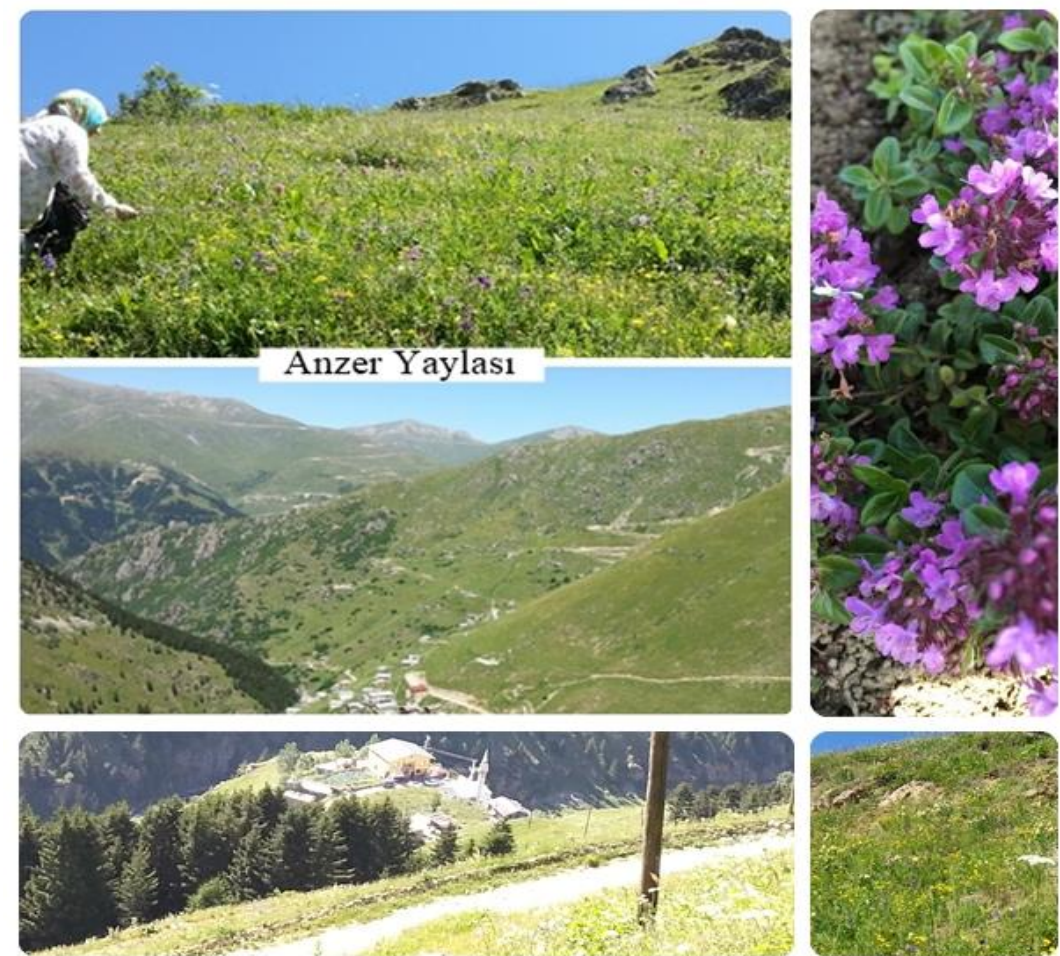

Şekil: 1. Bitki materyalinin toplandığı Anzer yaylasından görüntüler

Çizelge 1. Kekik (Thymus) taksonlarının toplandığı genotiplere ilişkin koordinat bilgileri

\begin{tabular}{|c|c|c|c|c|c|}
\hline Genotipler & Taksonlar & $\begin{array}{c}\text { Toplandığ } \\
\text { yer }\end{array}$ & $\begin{array}{l}\text { Yükseklik } \\
\text { (m) }\end{array}$ & Koordinat & $\begin{array}{c}\text { Toplama } \\
\text { tarihi }\end{array}$ \\
\hline TPCA1 & $\begin{array}{c}\text { Thymus praecox } \\
\text { Opiz subsp. } \\
\text { caucasicus(Wild. ex } \\
\text { Ronniger) Jalas var. } \\
\text { caucasicus }\end{array}$ & Anzer & 2106 & $\begin{array}{c}4037309 \\
\mathrm{~K} 4037 \\
836 \mathrm{D}\end{array}$ & $11 / 07 / 2014$ \\
\hline TPCA2 & $\begin{array}{c}\text { Thymus praecox } \\
\text { Opiz subsp. } \\
\text { caucasicus (Wild. ex } \\
\text { Ronniger) Jalas var. } \\
\text { caucasicus }\end{array}$ & Anzer & 1750 & $\begin{array}{c}4037816 \\
\mathrm{~K} 4032 \\
566 \mathrm{D}\end{array}$ & $11 / 07 / 2014$ \\
\hline TPCA3 & $\begin{array}{c}\text { Thymus praecox } \\
\text { Opiz subsp. } \\
\text { caucasicus (Wild. ex } \\
\text { Ronniger) Jalas var. } \\
\text { caucasicus }\end{array}$ & Anzer & 1534 & $\begin{array}{c}4038731 \\
\mathrm{~K} 4031 \\
955 \mathrm{D}\end{array}$ & $11 / 07 / 2014$ \\
\hline
\end{tabular}

Uçucu yağdaki önemli bileşenler RTEÜ Merkez Laboratuvarında Gaz Kromatografisi Shimadzu GCMS QP 2010 cihazında SPME (Solid Phase Microextraction) yöntemi kullanılarak belirlenmiştir.

Katı faz mikro ekstraksiyon (SPME) analizi çözücü gerektirmeden kuru numune üzerinden yapılan basit bir yöntemdir. Yöntemin esası polimerik sabit faz ile kaplanmış fuse silika fiber üzerinde uçucu yağların absorbe edilmesi ve fiber üzerinde absorbe edilen maddelerin enjeksiyon portunda isitılması desorpsiyonuna dayanır.

\subsection{Uçucu Yă̆ Bileșenleri Analizi}

Toplanan materyalin uçucu yağ bileşenleri Shimadzu GC-MS-QP 2010 A GC/MS sistemi ile analiz edilmiştir. 


\section{Sonuçlar ve Tartışma}

Gerek doğadan toplanan ve gerekse kültüre alınan Thymus praecox genotiplerinin uçucu bileşen analizi sonucunda toplam 24 bileşen tespit edilmiştir (Çizelge 2).

Çizelge 2. Thymus genotiplerine ait uçucu bileşen (\%) değerleri

\begin{tabular}{|l|c|c|c|c|c|c|}
\hline Genotipler & TPCA1 & & TPCA2 & & TPCA2 & \\
\hline \% Bileşen & Flora & Kültür & Flora & Kültür & Flora & Kültür \\
\hline Vinyl amyl carbinol & - & 0,15 & - & 0,81 & - & 0,68 \\
\hline Cymene <para> & 0,37 & 0,51 & 0,8 & 0,27 & 0,25 & 0,62 \\
\hline Eucalyptol & 0,22 & - & 0,22 & - & 0,68 & - \\
\hline Terpinene <gamma0> & 6,39 & 3,55 & 2,47 & 4,28 & 5,53 & 7,73 \\
\hline Sabinene hydrate <trans> & 1,23 & 0,62 & 0,67 & 0,37 & 0,68 & 0,94 \\
\hline Linalool & 15,97 & 7,96 & 10,99 & 3,08 & 9,75 & 5,44 \\
\hline Menthone & 4,41 & 0,51 & 4,77 & 0,34 & 6,27 & 1,72 \\
\hline Linalyl acetate & - & 2,29 & - & 0,77 & - & - \\
\hline Isoborneol & 6,71 & - & 6,73 & 0,19 & 9,22 & 1,07 \\
\hline Terpineol <alpha> & 2,31 & 2,17 & 1,4 & 1,97 & 1,35 & 0,35 \\
\hline Isougenly phenylacetate & 2,89 & 1,64 & 0,4 & 0,53 & 0,3 & 0,9 \\
\hline Pulegone & 1,15 & 0,1 & 1,29 & 0,64 & 1,25 & 1,36 \\
\hline Carvone & 2,09 & - & 3,09 & - & 0,17 & 0,4 \\
\hline Jasmone <(Z)> & 3,11 & 1,2 & 4,37 & 1,01 & 5,6 & 0,81 \\
\hline Myrlstlc alcohol & 2,3 & 1,14 & 2,36 & - & 2,45 & - \\
\hline Thymol & 20,82 & 42,12 & 20,48 & 40,14 & 39 & 16,21 \\
\hline Carvacrol & 9,44 & 20,76 & 4,82 & 20,15 & 6,44 & 53,57 \\
\hline Terplnyl acetate <alpha> & 9,98 & 11,65 & 31,37 & 15,7 & 3,99 & 3,86 \\
\hline Himachalene <alpha> & 4,07 & 2,04 & 1,06 & 2,01 & 3,71 & 1,71 \\
\hline Humulene <alpha> & 0,33 & 0,26 & 0,55 & 0,13 & 0,24 & 0,35 \\
\hline Isovaleric acid & 2,48 & 0,26 & 1,27 & - & 0,8 & - \\
\hline Acetoin & 1,2 & - & - & - & - & 1,86 \\
\hline Caryophyllene oxlde & 1,05 & - & 0,78 & 3,41 & 1,81 & 0,42 \\
\hline Pentadecanollde & 1,48 & 1,07 & 0,11 & 4,2 & 0,51 & - \\
\hline Toplam & 100 & 100 & 100 & 100 & 100 & 100 \\
\hline
\end{tabular}

TPCA1: Thymus praecox Opiz subsp. caucasicus (Wild. ex Ronniger) Jalas var. caucasicus (Anzer), TPCA2: Thymus praecox Opiz subsp. caucasicus (Wild. ex Ronniger) Jalas var. caucasicus (Anzer), TPCA3: Thymus praecox Opiz subsp. caucasicus (Wild. ex Ronniger) Jalas var. caucasicus (Anzer).

Elde ettiğimiz bulgular değerlendirildiğinde özellikle uçucu yağının kalitesini belirleyen thymol ve carvacrol bileşenlerinin floradan toplanan ve kültüre alınan genotiplere göre değişim gösterdiğini söyleyebiliriz Anzer yaylasının farklı rakımlarından toplanan ve kültüre alınan Thymus praecox Opiz subsp. Caucasicus (Wild. ex Ronniger) Jalas var. caucasicus (1534m, $1750 \mathrm{~m}$ ve $2106 \mathrm{~m}$ )'un uçucu yağ 1 sirasiyla \% 39-42.12 thymol, \% 20.7653.57 carvacrol ve \% 11.65-31.37 $\alpha$-terplnyl acetate'ce zengin bulunmuştur. Tümen vd (1995)'i Türkiye'nin farklı illerinden topladıkları T. praecox ssp. grossheimii var. grossheimii' ye ait iki örneğin uçucu bileşen içeriklerinin carvacrol \% 19, p-cymene $\% 10$; thymol \% 25 , p-cymene $\% 23$ olduğunu bildirmişlerdir Denemeye alınan genotiplerin uçucu yağının bileşenlerinin biçim zamanlarına göre farklılık meydana gelmiştir. Genotipler arasında uçucu bileşenler bakımından ortaya çıkan bu farklılı̆̆ın nedeni Lukas vd (2015)'nin, Toncer vd (2010)'nin, Hazzit ve Baaliouamer (2009)'nin ve Tümen vd (1995)'nin de belirttiği gibi uçucu bilşenler üzerinde yetiştirilen bölgenin ekolojik koşullarının, bitkinin hasat zamanlarının, olgunlaşma evrelerinin, farklı bitki kısımlarının, tür farklılığının ve genetik farklılı̆̆ın etkili olduğu söylenebilir.

Elde ettiğimiz bulgular değerlendirildiğinde özellikle uçucu yağının kalitesini belirleyen thymol ve carvacrol bileşenlerinin genotipler arasında göre geniş bir varyasyon gösterdiğini söyleyebiliriz. Bunun nedeninin araştırıcıların da belirttiği gibi genotiplerin genetik özelliklerinin birbirinden farklı olması ve ekolojik faktörlerin etkileri ile açıklanabilir. Monoterpenler üzerinde çevresel faktörlerin oldukça etkili

43 I P a g e

www.iiste.org 
olduğu ve uçucu yağının bileşiminin özellikle nemli ve sıcak havalardan etkilendiğini bildiren Burbott \& Loomis (1967)'le benzerlik oluşturmuştur.

Özellikle ticari olarak öneme sahip olan ve kekiği kekik yapan Thymol bakımından zengin olmaları anzer kekiğinin önemini artırmış ve adına dahada anlam katmıştır. Bu genotiplerin üzerinde çalışılarak farklı dönemlerdeki etken maddelerinin araştırılması ve bölge için en uygun hasat zamanının belirlenmesi bir sonraki çalışmamızın konusunu oluşturmaktadır.

\section{Literatür}

Anonim (2017). Türkiye İstatistik Kurumu Temel İstatistikler, https://biruni.tuik.gov.tr/medas/?kn=92\&locale (Erişim Tarihi: 03.03.2017)

Aydın E., Yurum, Ç., Kevseroğlu, K., \& Seyis F (2014). Doğadan Yoğun Olarak Toplanan Pazar Payı Yüksek Olan Önemli Tıbbi ve Aromatik Bitkilerin Risk Durumları, 23-25 Eylül 2014, Yalova, Bildiriler Kitabı: 281-286

Boukhebti, H., Chaker, A.N., Belhadj, H., Sahli, F., Ramdhani, M., Laouer, H. \& Harzallah, D. (2011). Chemical composition and antibacterial activity of Mentha pulegium L. and Mentha spicata L. essential oils. Der Pharmacia Lettre 3 (4): 267-275

Burbott, A.J., \& Loomis, W.D. (1967). Effects of light and temperature on the monoterpenes of peppermint. Plant physiology 42 (1): 20-28

Ceylan, A. (1995). Tıbbi Bitkiler-I (III. Basım), Ege Üniv. Ziraat Fakültesi Yayınları. Bornova / İzmir, Ders Kitab1, 135

Güner, A., Vural, M., \& Sorkun, K. (1987). Rize Florası, Vejetasyonu ve Yöre Ballarının Polen Analizi, Hacettepe Üniversitesi. Ankara. Tübitak Proje No: T.B.A.G.-650

Kahya, E. (2017). El-Kanun Fi't-Tıbb.2.Cilt. Atatürk Kültür Merkezi Yayınları. ISBN: 9751607713, Ankara.

Lukas, B., Schmiderer C., \& Novak, J. (2015). Essential oil diversity of European Origanum vulgare L. (Lamiaceae). Phytochemistry 119: 32-40.

Özgüven, M., \& Tansi, S. (1998). Drug yield and essential oil of Thymus vulgaris L. as in influenced by ecological and ontogenetical variation. Turkish Journal of Agriculture and Forestry 22 (6): 537-542.

Toncer, O., Karaman, S., Kizil, S., \& Diraz, E. (2009). Changes in essential oil composition of oregano (Origanum onites L.) due to diurnal variations at different development stages. Notulae Botanicae Horti Agrobotanici Cluj-Napoca 37 (2): 177

Tümen, G., Kirimer, N., \& Başer, K. (1995). Composition of the essential oils ofThymus species growing in Turkey. Chemistry of Natural Compounds 31 (1): 42-47 